\title{
El arbitraje de las revistas médicas, la gestión editorial en red y la calidad de la publicación científica*
}

\author{
The peer-reviewing of medical journals, the \\ editorialmanagement in network and the quality of the \\ scientific publication
}

La era de las revistas científicas nació en el siglo xVII con la aparición de la mítica Philosophical Transactions of the Royal Society, en el Reino Unido, y de la menos famosa Journal des Savants, en Francia, ambas en 1665. Entonces, y a lo largo de casi dos siglos, no existía el arbitraje formal a cargo de especialistas independientes. El control de calidad se realizaba a posteriori y por conducto de apasionadas discusiones sobre lo ya publicado en círculos de expertos.

El "arbitraje científico", o peer review para los anglosajones, expresión que podría traducirse como "revisión crítica de los resultados de un artículo científico a cargo de sus pares", abarca la actividad de revisores y editores y se ocupa de determinar si un trabajo merece o no ser publicado, financiado o admitido en una conferencia arbitrada. Siendo así, la condición de creación científica alcanza la condición de proceso social, no solo individual.

La potencial inoperancia de dejar en manos de los editores la decisión (sin participación de árbitros) se puso de manifiesto en algunos casos dramáticos, tal como el que tuvo lugar en 1937 con el célebre trabajo de Hans Krebs sobre el ciclo del ácido cítrico, originalmente rechazado por Nature, y que más tarde sería la pieza clave para que el autor fuera galardonado con el premio Nobel. Bien conocido hoy por los científicos de todas las disciplinas, el peer review no vino, sin embargo, a convertirse en una herramienta medular para los editores de revistas médicas hasta hace unos pocos decenios. Y solo desde muy recientemente -década de los setenta- ha devenido un elemento ineludible de todo proceso editorial que aspire a la excelencia.

A los árbitros les toca evaluar si las preguntas de investigación o los propósitos de un ensayo son pertinentes; si la metodología seguida es correcta y si los resultados constituyen un aporte a lo que ya se conoce; si los autores se han apoyado en las referencias correctas $y$, en buena medida, si la obra responde a las normas éticas establecidas por la revista. No se espera del sistema, sin embargo, que tenga capacidad para detectar fraudes. 
El mecanismo no está exento de aristas conflictivas. Se ha señalado, por ejemplo, que los árbitros tienden a ser particularmente críticos cuando las conclusiones no concuerdan con sus propias opiniones, y más indulgentes con los trabajos que se hallan en el caso opuesto. Sin embargo, a pesar de diversos esfuerzos alternativos, no se cuenta por el momento con ningún recurso más eficiente para tratar de acrisolar la calidad de una contribución.

La aplicación de este sistema es objeto de algunas polémicas (algunos sostienen que debe desarrollarse en un marco de anonimato; otros que debe ser enteramente transparente para árbitros y autores, por poner un ejemplo) y es objeto de permanente examen. Desde hace unos 20 años tiene lugar incluso una reunión internacional enteramente destinada al estudio del comportamiento y formas de optimizar el peer review (la sexta edición del Congreso de Peer Review and Biomedical Publications, como se denomina en inglés, se celebró en Vancouver, Canadá, en el año 2009).

Algunas prestigiosas publicaciones (por ejemplo, British Medical Journal) han decidido, desde hace unos años, renunciar a la práctica de mantener secreta la identidad de los árbitros y optaron por el llamado open peer review; otras, como PlosONE, que forma parte del proyecto Public Library of Science se suman a la lógica de la llamada Web 2.0 y han establecido que la revisión de los artículos continúe después de haber sido publicados, sobre la base de que los lectores puedan hacer comentarios, a la vez que los autores pueden incorporar rectificaciones o insertar réplicas a dichos comentarios.

El Centro Nacional de Información de Ciencias Médicas tiene entre sus encomiendas la de fomentar la publicación científica de calidad en el ámbito de la salud en Cuba. Consecuentemente, se propone conseguir que todas las revistas del sector apliquen con el máximo rigor posible sus sistemas de arbitraje. Se trata de un procedimiento que, a pesar de no ser actualmente objeto de discusión como tal, se presta a algunas dudas, conflictos y concepciones erróneas. Entre otros, pueden señalarse problemas que van desde los más elementales, tales como que simplemente no se realiza, o que las reglas se flexibilizan para determinados autores hasta algunas más sutiles, como que no siempre se desarrolla según los estándares de estricta confidencialidad que se recomiendan.

Por otra parte, ocasionalmente se desdeña la importancia de esta tarea por parte de las autoridades y hasta de los propios autores. Es natural que estos se impacienten cuando el proceso editorial se alarga, pero menos lógico es que se irriten cuando sus trabajos son rechazados o devueltos para la reelaboración de sus contenidos. Parte de la cultura científica que tenemos que desarrollar exige que los autores comprendan que un árbitro virtualmente nunca es un "enemigo"; más aun, que por lo general es un aliado, ya que procura mejorar los artículos remitidos o incluso evita que vea la luz un trabajo deficiente, algo que siempre terminará por dañar la reputación de su autor.

La Revista Cubana de Ciencias de la Información en Salud (ACIMED) se ha propuesto mantener las más altas cotas de rigor en esta materia. Entre los diversos modelos posibles, nuestra revista intenta preservar la integridad del proceso de revisión por pares, de modo que la identidad de los autores no sea conocida por los árbitros ni viceversa. Se procura así que el prestigio de los autores, cualquiera que sea, no gravite sobre la decisión, así como que no se penalice lo novedoso ni se refuerce a priori la autoridad constituida. 
Para conseguir estos propósitos, el Comité Editorial hace una cuidadosa selección de los árbitros para cada trabajo, elige nunca menos de dos colegas que trabajan independientemente (ocasionalmente tres y hasta cuatro árbitros) y se mantiene un control minucioso de los intercambios producidos. Para esto ha resultado extremadamente útil el empleo de la plataforma de gestión de revistas en red (Open Journal System), por cuyo conducto se agiliza y ordena eficientemente este complejo proceso.

Aunque actualmente mantenemos la estrategia de arbitraje según las líneas arriba bosquejadas, reconocemos que las nuevas realidades tecnológico-comunicativas pudieran aconsejar modificaciones del modelo valorativo. Estaremos atentos a las experiencias que se vayan desarrollando; pero también, y sobre todo, a los comentarios, sugerencias o reflexiones que nuestros lectores y autores nos hagan llegar en forma de cartas al Director o de artículos que aborden esta importante temática.

DrCs. Luis Carlos Silva Ayçaguer

* Reproducción autorizada de ACIMED. 2011;22(2):91-3. 